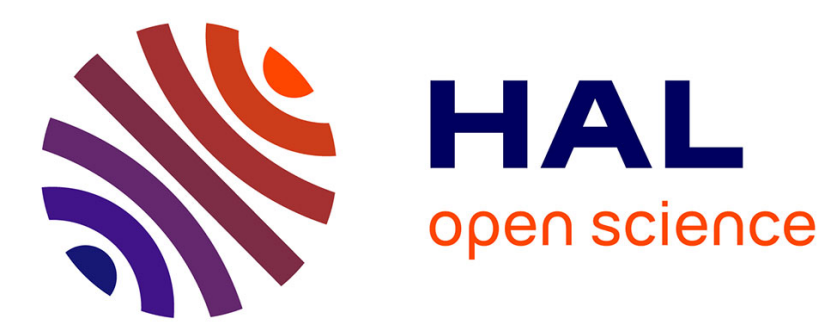

\title{
Eradication of Bacteria Via Electropulsation
}

J. Teissié, D. Zerbib

\section{To cite this version:}

J. Teissié, D. Zerbib. Eradication of Bacteria Via Electropulsation. Encyclopedia of Interfacial Chemistry, 7, pp.224-234, 2018, Surface Science and Electrochemistry. hal-01883434

\section{HAL Id: hal-01883434 \\ https://hal.science/hal-01883434}

Submitted on 28 Sep 2018

HAL is a multi-disciplinary open access archive for the deposit and dissemination of scientific research documents, whether they are published or not. The documents may come from teaching and research institutions in France or abroad, or from public or private research centers.
L'archive ouverte pluridisciplinaire HAL, est destinée au dépôt et à la diffusion de documents scientifiques de niveau recherche, publiés ou non, émanant des établissements d'enseignement et de recherche français ou étrangers, des laboratoires publics ou privés. 


\section{Eradication of Bacteria Via Electropulsation}

J Teissié and D Zerbib, IPBS and LISBP, University of Toulouse, CNRS, INRA, INSA, Toulouse, France

(C) 2018 Elsevier Inc. All rights reserved.

\begin{tabular}{|c|c|}
\hline Introduction & 225 \\
\hline Bacteria & 225 \\
\hline Diderm-Lipopolysaccharide Bacteria Cell Envelope (Glycobacteria) & 226 \\
\hline The outer membrane & 226 \\
\hline Diderm cell-wall: the PG & 226 \\
\hline The periplasm & 226 \\
\hline The inner membrane & 227 \\
\hline Monoderm Bacteria Cell Envelope & 227 \\
\hline Monoderm PG & 227 \\
\hline Teichoic acids (TA) & 227 \\
\hline Surface proteins & 227 \\
\hline The cytoplasmic membrane & 227 \\
\hline Bacterial S-Layer & 227 \\
\hline Conclusions & 228 \\
\hline Electropermeabilization & 228 \\
\hline Bacterial Eradication & 228 \\
\hline General Protocol & 228 \\
\hline Protocols Depend on the Bacterial Species & 228 \\
\hline Control by the Growth Conditions & 229 \\
\hline Post Pulse Effects & 230 \\
\hline Reactive Oxygen Species Generation & 230 \\
\hline Effect of the Buffer $\mathrm{pH}$ & 230 \\
\hline Effect of the Buffer Conductivity & 230 \\
\hline Ultrastructural Analysis of PEF Treated Bacteria & 231 \\
\hline Conclusions & 231 \\
\hline Acknowledgements & 232 \\
\hline References & 232 \\
\hline Further Reading & 233 \\
\hline Relevant Websites & 234 \\
\hline
\end{tabular}

\section{Glossary}

Cell wall A tough, rigid layer that surrounds cells such as bacteria.

Electropermeabilization Induction of transport pathways in a cell membrane by electropulsation.

Electropulsation Delivery of a calibrated electric pulse on a biological sample such a bacterial suspension.

Prokaryote A cellular organism where nuclear membrane, organelles (except ribosomes) are not present in the cytoplasm.

Pulsed electric field Repetitive delivery of a short lived electric voltage on a conductive solution.

$\begin{array}{ll}\text { Nomenclature } \\ \text { AFM } & \text { Atomic force microscopy } \\ \text { CFU } & \text { Colony forming unit } \\ \text { CL } & \text { Cardiolipin } \\ \text { CM } & \text { Cytoplasmic membrane } \\ \text { CW } & \text { Cell wall } \\ d & \text { Gap between the electrodes (m) } \\ \text { E } & \text { Field }(\mathrm{V} / \mathrm{m}) \\ \text { GlcNAc } & \text { N-acetyl glucosamine } \\ I & \text { Current (A) }\end{array}$




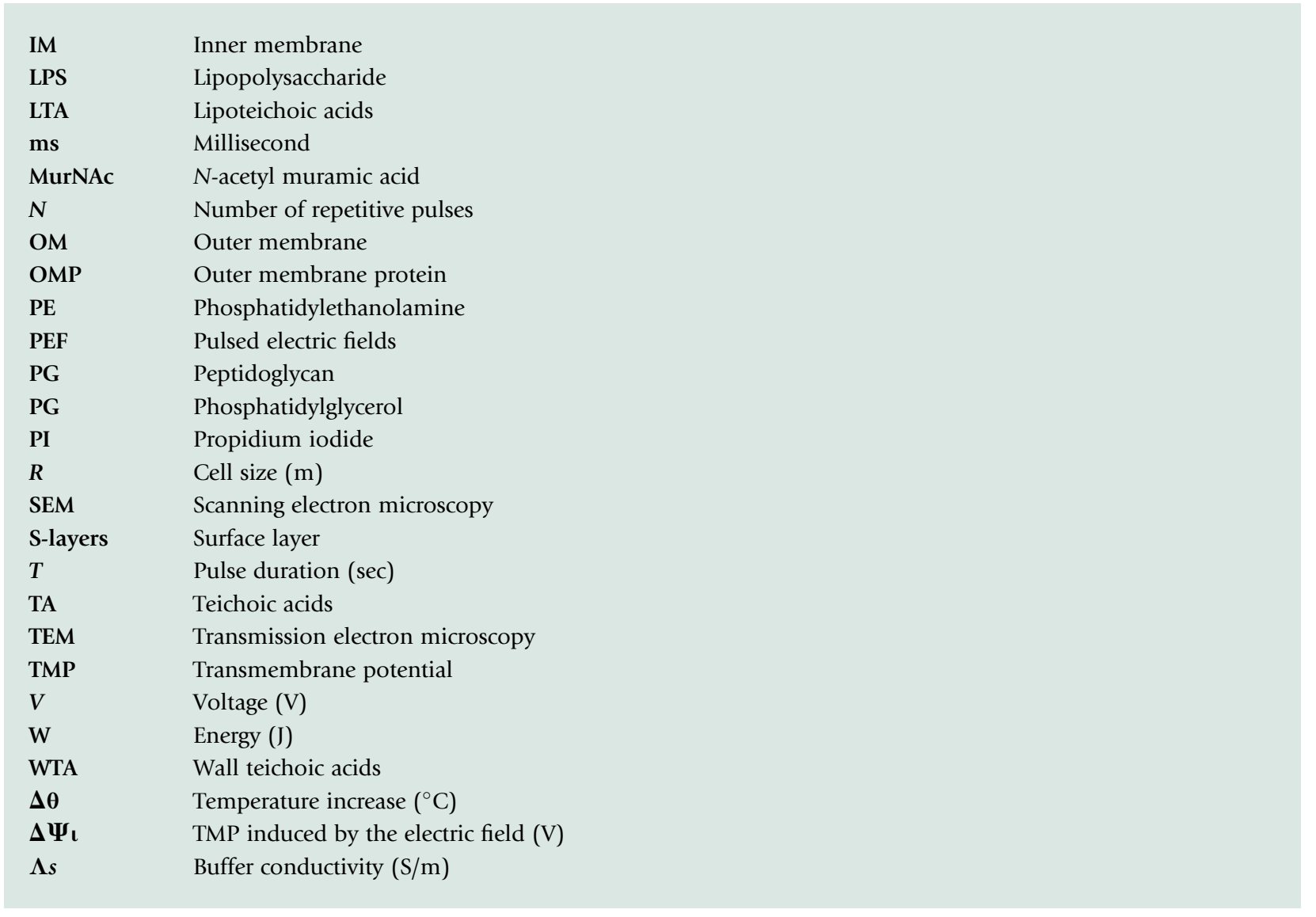

\section{Introduction}

Pulsed electric fields (PEF) are known to induce cell membrane electropermeabilization and its associated cell loss of viability. Since the pioneering results published 50 years ago, ${ }^{1-3}$ describing electroeradication of microorganisms, there has been a lot of interest in the translational developments of these observations. The treatment of large volumes of bacterial suspension was obtained by the development of flow processes. ${ }^{4}$ Three main fields of industrial applications are present: bacterial eradication (waste water disinfection, food treatment by cold sterilization), cytoplasmic content extraction, and genetic engineering by plasmid introduction. One of the limiting problems in those industrial developments is that present knowledge on the physicochemical mechanisms supporting the reorganization of the cell membrane and bacterial wall remains very limited. Electropermeabilization is more than simply punching holes in a one-lipid bilayer, as assumed in the early versions of "electroporation". ${ }^{5,6}$ A state-of-the-art description of our knowledge of the biophysical aspects is given in the companion chapter.

The physiology of the bacteria controls many parameters. This is indeed very complex in microbiology. The associated destabilization of the membrane selective permeability is stressful for the cells and results in loss of cell viability. Events are present at the level of the plasma membrane (as observed mostly with mammalian cells), but with a control and/or feedback on the wall organization.

This chapter will present a description of the present knowledge of the organization of the bacterial membrane and wall, followed by a discussion of the effects linked to the application of an electrical field (i.e., current) on an ionic bacterial suspension, and methods of controlling the alteration of the membrane and wall in pulsed bacteria.

\section{Bacteria}

The bacterial envelope, the primary function of which is probably to protect the cell from the environment ${ }^{7,8}$ is an active component essential for survival, division, adaptation, morphogenesis, and pathogenesis. In addition to osmotic pressure protection and bacterial shape control (spherical in coccus, rod in bacillus), it enables the entry of nutrients, vitamins, and cofactors and the efflux of toxins and unwanted metabolites. ${ }^{8}$ Metabolic energy production is controlled by the envelope. Electron transport chains induce the electrochemical proton gradient needed to yield the proton motive force in the bacterial membrane, ${ }^{9}$ as well as with cytoplasmic 
ATP production by oxidative phosphorylation. The cell envelope is able to sense and transduce signals, allowing the bacterium to resist and adapt to environmental stresses and changes. ${ }^{10}$

In addition to its multiple active roles, the envelope provides a physical barrier protecting the bacteria from the environment. ${ }^{8,11}$ The cell wall (CW) supplies the bacterial shape, provides the bacterial resistance to osmotic pressure, and prevents the envelope from rupture. It is porous, and these holes are chemically filled with proteins and polysaccharides organized in supra-molecular networks. The wall is coated and reinforced by one or two hydrophobic selective barriers known as the bacterial membranes.

Bacteria were differentiated from one another using the Gram staining procedure which originated more than a century ago. The structure and composition of the bacterial envelope affected the staining procedure, categorizing bacteria as either Gram-positive or Gram-negative. The bacterial envelopes are now defined with the number of the membranes that they contain: the cells are either diderms or monoderms. Cells are also classified according to the presence of lipopolysaccharides (LPS) in the diderm envelopes. This classification, based on the number of bacterial membranes, is more appropriate in evaluation of the impact of electric field effects on the bacterial envelopes.

\section{Diderm-Lipopolysaccharide Bacteria Cell Envelope (Glycobacteria)}

Typical diderm-LPS, Gram-negative bacteria examples such as Escherichia coli have a cell envelope composed of three layers with an average thickness of $35 \mathrm{~nm}$. The inner membrane (IM) or cytoplasmic membrane (CM) (from 5 to $8 \mathrm{~nm}$ ), and the outer membrane (OM) delineate the hydrophilic periplasm formed by a thin layer of peptidoglycan (PG) constituting the CW. The PG thickness varies between $6 \mathrm{~nm}$ (in E. coli) and $2.4 \mathrm{~nm}$ in Pseudomonas aeruginosa. ${ }^{12}$ Both membranes are hydrophobic and semipermeable. In addition to lipids and carbohydrates, the three layers contain proteins.

\section{The outer membrane}

The OM is an asymmetric lipid bilayer essential for its protective function. Phospholipids are only found in the inner leaflet and consist, In E. coli, of $90 \%$ of the zwitterionic phospholipid phosphatidylethanolamine (PE), $6 \%$ of the anionic (charged) phospholipid phosphatidylglycerol (PG), and $4 \%$ of the anionic phospholipid cardiolipin (CL) (or diphosphatidylglycerol). ${ }^{13}$ The inner leaflet of the OM is more rigid than the IM because it contains more saturated fatty acids and has a smaller net negative charge. In Glycobacteria, i.e., diderm-LPS-bacteria, ${ }^{14,15}$ the outer leaflet of the OM is mainly composed of the lipid moiety of anionic glycolipids: Lipid A from LPS. ${ }^{16}$ The LPS itself is a glucosamine disaccharide bearing six or seven acyl chains (lipid A) linked with a polysaccharide core and an extended polysaccharide chain called the O-antigen. ${ }^{16}$ LPS is involved in the surface net charge of the envelope and is mainly responsible for the overall hydrophobicity of LPS containing bacteria. The acyl chains of LPS are saturated and thus favor LPS packing. The packing is reinforced by LPS negative charges neutralization with divalent cations like $\mathrm{Mg}^{2+}$ and $\mathrm{Ca}^{2+17}$ and is affected by their chelation by EDTA. In summary, the LPS leaflet is a very effective hydrophobic barrier, a property that is increased by the hydrophilic selectivity of embedded porins for molecules larger than $700 \mathrm{Da}{ }^{17}$

Proteins in the OM [outer membrane proteins (OMPs)] are mainly of two types: lipoproteins and $\beta$-barrel proteins. ${ }^{8}$ In E. coli, there are more than 100 different OM-lipoproteins. ${ }^{18}$ Their $N$-terminal cysteins are modified by thioether-linked diacylglycerol and amino-linked acyl chains which allow the lipid moieties of lipoproteins to embed in the inner leaflet of the OM. $\beta$-barrel proteins are cylinder-shaped integral transmembrane proteins formed by $\beta$-sheets. Some OMPs are porins, allowing the passive diffusion of small molecules participating in the OM selectivity. ${ }^{19}$

\section{Diderm cell-wall: the PG}

PG layers cover the CM of nearly all bacteria. PG, also called murein, is the bag-shaped rigid exoskeleton of bacteria: the sacculus. ${ }^{20}$ It determines the bacterial shape ${ }^{21}$ and is made of glycan strands cross-linked with short specific peptides. ${ }^{12}$

PG prevents bacteria from cell lysis in low osmolarity media. Its enzymatic hydrolysis by lysozyme induces the loss of cell shape and provokes the formation of spheroplast. Spheroplasts are sensitive to low osmolarity media. The most common organization of PG is the following. Linear glycan PG strands are made up of alternating $N$-acetyl glucosamine (GlcNAc) and $N$-acetyl muramic acid (MurNAc) linked in $\beta-1 \rightarrow 4$. MurNAc is substituted by uncommon pentapetide containing rare D-amino acids. In nascent PG, the pentapeptide is often L-Ala- ${ }_{D}-G l u-m A 2 p m$ (meso-diaminopimelic acid) - ${ }_{D}$-Ala- ${ }_{D}$-Ala. The last D-Ala is generally absent from mature PG. Those peptides are crosslinked together generally between the penultimate D-Ala and the mA2pm at position 3. Thus, linear glycan strands are crosslinked by peptide bridges of seven amino acids.

Chemical composition of PG is well known in numerous species. Debate centers on the 3D architecture of PG in different bacteria. ${ }^{12,21}$ The classical "horizontal layers model" proposes an architecture in which the glycan strands are parallel to the $\mathrm{CM}^{22}$ The "vertical scaffold model" proposes that the peptides are parallel to the membrane, whereas the glycan strands run perpendicular to the long axis of rod-shaped bacteria. ${ }^{23}$

\section{The periplasm}

The periplasm was defined originally as being an aqueous compartment located between the OM and the CM. It is a hydrophilic and oxidizing "space" between the membranes. The periplasm contains the $\mathrm{CW}^{24}$ and is rich in proteins. Proteins are degradation enzymes (RNase or alkaline phosphatase), periplasmic binding proteins, involved in sugar and amino acid transport and in chemotaxis, and "chaperones" involved in envelope biogenesis. 


\section{The inner membrane}

In contrast to the OM, the IM of diderm is a symmetric phospholipid bilayer. In E. coli, the IM is composed of 75\% of the zwitterionic phospholipid phosphoethanolamine (PE), 20\% of the anionic phospholipid phosphatidylglycerol (PG), 5\% of the anionic phospholipid cardiolipin (CL), and a low fraction of phosphatidylserine (PS). Energy production, lipid biosynthesis, and protein transport and secretion are the main functions accomplished within the IM.

\section{Monoderm Bacteria Cell Envelope}

Monoderm bacteria are protected from the turgor pressure by PG layers several times thicker than in diderms. The thickness of monoderm envelopes varies together with the PG thickness that is also variable: $20 \mathrm{~nm}$ in S. aureus to $34 \mathrm{~nm}$, in B. subtillis for example. ${ }^{12}$ This tight CW is reinforced by the presence of long anionic polymers: the teichoic acids (TA). ${ }^{25}$ The external proteins of monoderm bacteria are either covalently attached to the PG, partially inserted in the CM, linked to CM lipids anchors, or attached to teichoic acids. ${ }^{26}$

\section{Monoderm PG}

The PG of monoderms is made of glycan strands composed of disaccharide repeats linked together with pentapeptide units. The classical monoderm PG chemical composition is identical to the one of diderm bacteria. The linear glycan strands of PG are made up of alternating $N$-acetyl glucosamine (GlcNAc) and $N$-acetyl muramic acid (MurNAc) linked in $\beta$ - $1 \rightarrow 4$, and are crosslinked together with short specific peptides. The major difference with diderm PG is in the PG thickness; the Gram-positive PG can be 30-100 nm thick, whereas the Gram-negative is only a few nm thick. Among the Gram-positive bacteria, the differences between PG structures are mainly based on the type of crosslinking of the glycan strands by peptides. ${ }^{27}$ Branched peptides are attachment sites of specific PG covalently associated proteins.

\section{Teichoic acids (TA)}

TA are formed by a disaccharide linkage unit and an anionic chain of polyglycerolphosphate or polyribitolphosphate repeats decorated with saccharides and positively charged D-alanyl esters. Wall teichoic acids (WTA) are covalently attached to $\mathrm{PG}^{28}$ while lipoteichoic acids (LTA) are linked to the head groups of CM lipids. TA represent about $60 \%$ of the cell envelope mass and are mainly responsible, together with $\mathrm{PG}$, for the envelope structure and function. These long anionic polymers are critical determinants of the envelope surface's net charge and hydrophobicity. The WTA are coupled to PG and the LTA are anchored in the CM. WTAs are found perpendicular to the PG layers. LTA are anchored in the CM through embedded glycolipids. Because they contain fewer repeat units than WTA, they do not span beyond the PG. The negative surface net charge of the Gram-positive envelope is essential, and when TA are absent from a given species, they are replaced by other polyanionic polymers containing either carboxylate or sulfate groups. Cations binding on TA induce the formation of a cationic network that increases the rigidity of the envelope.

\section{Surface proteins}

TA are involved in bacterial adherence together with adhesins. Most of them are covalently attached to the stem peptide of PG but some are only interacting with either PG or TA. ${ }^{26}$ Other surface proteins are anchored through helices inserted in the lipid leaflet of the CM. Some other surface proteins are involved in CW modeling and are noncovalently linked to either PG or TA.

\section{The cytoplasmic membrane}

The monoderm CM is a symmetrical phospholipid bilayer like the diderm IM, but the proportions of zwitterionic phospholipid phosphatidylethanolamine (30\% PE) and anionic phospholipid phosphatidylglycerol (70\%, PG) are different from those of diderms. The monoderm CM has a higher negative surface charge. ${ }^{29}$ Monoderm CM contains undecaprenyl-phosphate necessary for the envelope biogenesis together with $\alpha$-helical anchored lipoproteins and the saccharide moiety of LTA.

\section{Bacterial S-Layer}

S-layers (surface layer) are paracrystalline protein lattices found in both Gram-positive and Gram-negative bacteria. In Grampositive bacteria, the S-Layer is noncovalently attached to PG or other cell-wall components. In Gram negative bacteria, the S-Layer is attached to the LPS. S-layers are each homogenous. In a given bacterium, they are mostly composed of one protein or glycoprotein species, but a single strain can express different S-layers depending on culture conditions. The degree of glycosylation and glycan composition of glycoproteins is greatly variable. The S-layer proteins are slightly similar to each other, but they are usually acidic or hydrophobic. S-layer proteins possess a core "heavy" domain that forms the basic morphological unit cell, and a lighter domain that provides connectivity between core units. The core is usually oriented toward the cell envelope, giving rise to a corrugated inner surface overall. By contrast, the outer surface appears smooth despite highly variable and species-specific ultra-structures. Between $30 \%$ and $70 \%$ of the unit cell volume is occupied by the protein, which leads to the formation of identical and well-defined pores with a diameter of $2-8 \mathrm{~nm} .^{30}$ 


\section{Conclusions}

The bacterial cell envelopes are complex and dynamic, and play fundamental roles in the protection of bacteria. The PG is essential in the maintenance of the rigidity and the shape of bacteria. It is also essential for protecting the cell from the strong osmotic pressure of the cytoplasm.

\section{Electropermeabilization}

Electropermeabilization is the result of the delivery of PEF on a cell suspension either with a batch or a flow process. Electropermeabilization of the cell membrane is a multistep process occurring on different time scales:

1. Induction step (ns). The electric field induces a membrane potential difference increase that is a function of the cell size. When it reaches a critical value (about $200 \mathrm{mV}$ ), local "defects" appear.

2. Expansion step $(\mu \mathrm{s})$. Defects expend and new defects appear as long as the field above the critical value is present. A high conductivity is present across the membrane.

3. Stabilization step (ms). As soon as the field intensity is lower than the critical value, a recovery process takes place within a few milliseconds, bringing the membrane to the "permeabilized state" with a low but significant conductivity.

4. Resealing step (s, min). A slow resealing of the defaults occurs. The membrane conductivity decreases back to its prepulse value.

5. Memory effect $(\mathrm{h})$. Some changes in the membrane properties remained present on a longer time scale, but the cell behavior returned to normal.

This description cannot discriminate between the $\mathrm{CM}$ of diderms and monoderms. The case of the OM may be different as there are conducting pathways (OMP) that bypass step one.

By a proper choice of pulsing conditions (field strength, pulse duration, number of repetitive pulses), Step 4 can be eliminated. Permeabilization is therefore irreversible. Cell viability is not preserved as expected for bacterial eradication. It still remains to evaluate the process in microorganisms in which the membrane (target of electropermeabilization) is protected by a complex wall organization.

\section{Bacterial Eradication}

\section{General Protocol}

Irreversible electropermeabilization is a physical (green) approach for microbial pathogens eradication. This membrane alteration is routinely detected by the penetration of a nonpermenant dye, such as propidium iodide (PI), and its detection in the cell (Fig. 1)

Electroeradication was developed for its industrial use for the food industry and the treatment of waste water. The delivery of high field (more than $20 \mathrm{kV} / \mathrm{cm}$ ) short (a few microseconds) pulses was enough to result in loss of viability in treated bacteria. Viability was evaluated by counting the number of colonies (CFU) after the pulse delivery (Fig. 2). The treatment was efficient, and the ratio of the surviving bacteria to the control sample was evaluated on a long scale ${ }^{31-36}$ (Fig. 2).

PEF treatment has received much attention as a cost efficient nonthermal food industrial processing and preservation technology. No chemical additives are needed, and temperature effects are limited and short-lived. The running costs are limited mainly to the electrical energy delivered under optimized conditions. The design of the pulsing chambers is of course critical in this view. ${ }^{37}$

Eradication presents a way to inactivate several Log10 cycles of the microbial population. Process parameters strictly control the efficiency of microbial inactivation by PEF treatment. ${ }^{33,38}$ The efficiency of PEF treatment depends on field parameters. The main process parameters are electric field strength, pulse duration, and number of pulses; they can be combined under energy applied per mass unit (specific energy). The general observations are:

1. The field strength must be larger than a critical value. Eradication then increases with the increase in the field strength.

2. Pulse (cumulated) lengths are larger than hundreds of nanoseconds and can be as large as a few milliseconds.

3. The loss of viability increases with the increase in the number of pulses.

Most protocols use trains of repetitive high-field (more than $20 \mathrm{kV} / \mathrm{cm}$ up to $75 \mathrm{kV} / \mathrm{cm}$ ), short (in the order of the microsecond) pulses in a poorly conductive buffer (to limit the associated Joule heating and the peak current to be delivered, i.e., the energy cost and the safety from the design of the generator). ${ }^{39,40}$ Treatment time (effective time) depends on the number of pulses $(\mathrm{N})$ and the width of the pulses, and is in the ms time range (meaning $\mathrm{N}$ is of the order of 1000 and rod orientation is affected). These conditions were observed to be valid not only for the food industry but for the treatment of waste water $\left({ }^{41}\right)$.

\section{Protocols Depend on the Bacterial Species}

Pulsing protocols were dependent on the nature of the treated bacteria in a way that could not be simply explained by the predicted dependence of the field effect on the size of the treated bacteria. An apparent effect of morphology on membrane permeabilization was observed, and larger cells were more easily permeabilized than smaller cells. Gram-positive bacteria (L. monocytogenes) survived 
(A)

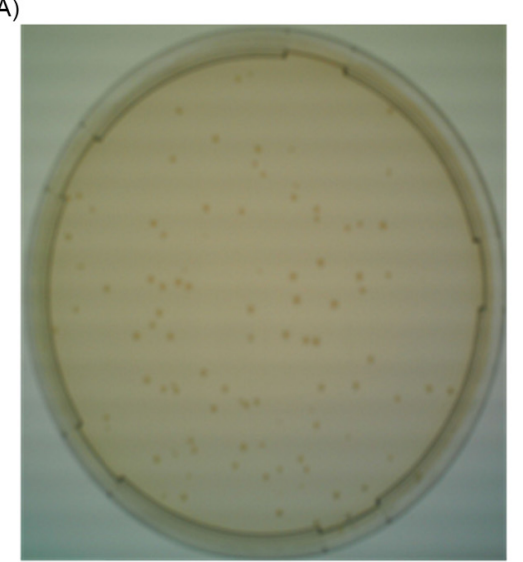

(C)

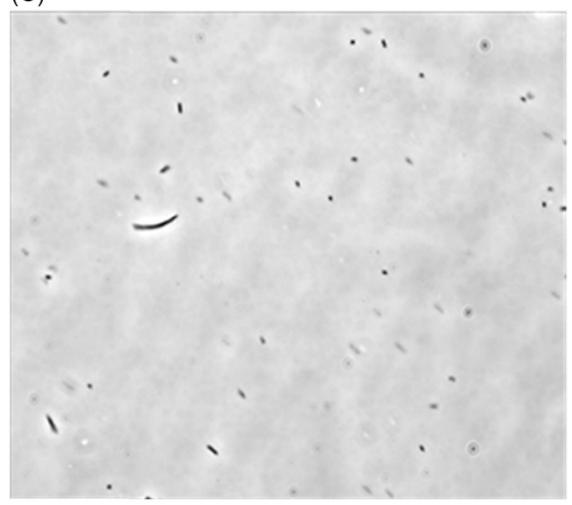

$(E)$

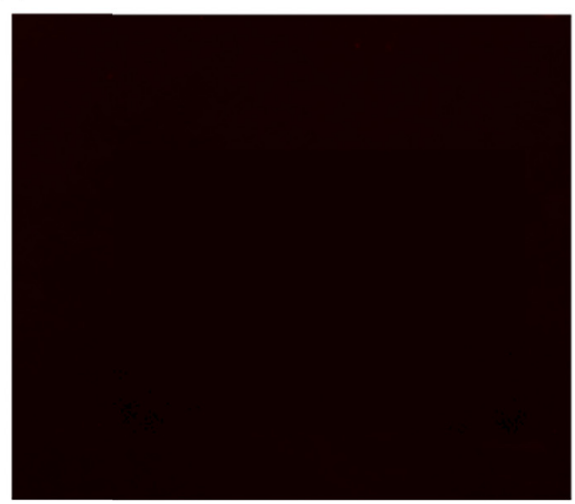

(B)

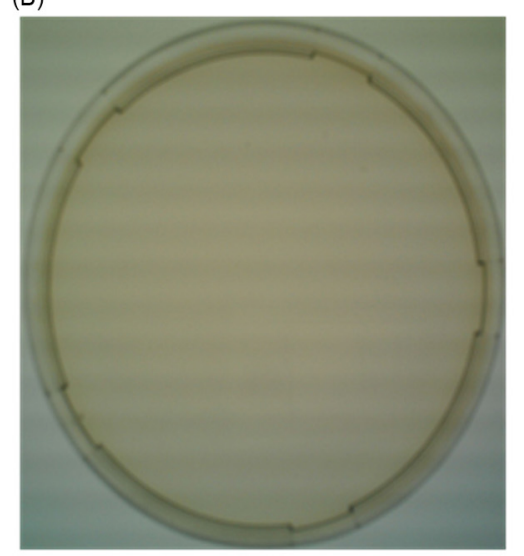

(D)

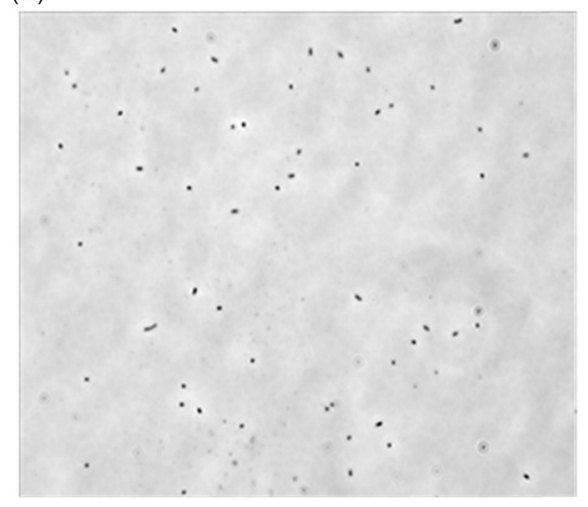

$(\mathrm{F})$

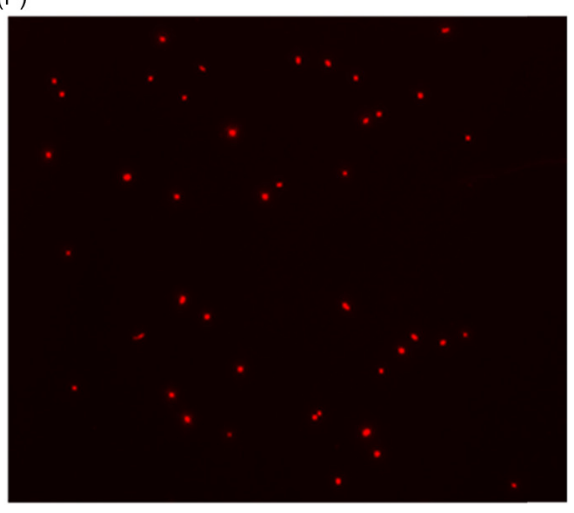

Fig.1 Effect of PEF on E. coli viability. $10^{4}$ pulses were delivered on an E. coli culture in tap water $(7.5 \mathrm{kV} / \mathrm{cm}, 5$ micros, $1 \mathrm{kHz}$, alternate polarity). First line colonies growing on an Agar dish overnight after appropriated dilutions ( $A$, control; $B$, pulsed). Second line bacteria observed under a phase contrast microscope (C, control; D, pulsed). Third line bacteria observed under a fluorescence microscope after PI staining (E, control; $F$, pulsed). All pulsed cells are stained by PI indicative of their irreversible membrane destruction.

the PEF treatment better at neutral $\mathrm{pH}$ than the Gram-negative species. The differences in cell membrane composition and wall organization appeared involved in their inactivation: the OM does not bring any protective effect. ${ }^{42}$

\section{Control by the Growth Conditions}

The growth phase was a decisive parameter. Cells in the stationary phase were less sensitive and required higher field and more successive pulses for the eradication. Spores were resistant. These prepulse cultivation treatments were acting on the physiology of the microorganism and on its metabolic biochemistry. Basic research on the role of the composition of cell membrane and wall on the efficiency of PEF treatment are still missing. ${ }^{43-45}$ Biofilms were destroyed. ${ }^{46}$ 


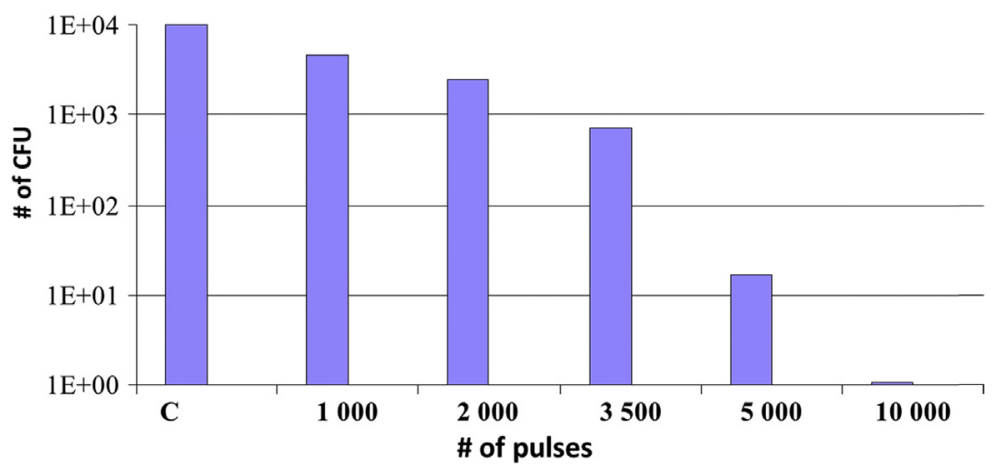

Fig. 2 Evolution of the number of CFU after the delivery of different number of pulses. $10^{4}$ pulses were delivered on an E. coli culture in tap water $(7.5 \mathrm{kV} / \mathrm{cm}, 5$ micros, $1 \mathrm{kHz}$, alternate polarity). A log scale is use for the number of CFU.

Growth temperature was another factor affecting the resistance of Escherichia coli to electroeradication. Cells grown to the stationary phase at low $\left(10^{\circ} \mathrm{C}\right.$ and $\left.20^{\circ} \mathrm{C}\right)$ temperature were more resistant than those grown at the physiological temperature. Again, the consequences of these thermal effects on the physiology of the bacteria was a modification of the lipid composition of the plasma membrane. ${ }^{40,47,48}$ Such a negative effect of a low temperature growth conditions on electroeradication was observed on the Gram-positive Listeria whatever the growth phase of the PEF-treated bacteria. ${ }^{49}$

Microorganisms could adjust their membrane lipid fatty acyl chain content composition in response to changes in growth temperature to preserve membrane function such as enzyme activity. In order to keep a full metabolic activity at low temperatures, fatty acid chains of E. coli membrane were modified by an increase in the synthesis of unsaturated fatty acids with the expense of saturated fatty acids. A more "fluid" membrane resulted that was observed to be more PEF-resistant.

\section{Post Pulse Effects}

Furthermore, the process was not an all-or-nothing phenomenon. PEF triggered two classes of effects on the pulsed bacteria: short term and long term responses. Survival was controlled by the postpulse incubation conditions with the definition of a survival buffer. This indicates that loss of viability is not only the result of a mechanical stress, but also that a metabolic response of the pulsed bacteria was involved. ${ }^{50-52}$

\section{Reactive Oxygen Species Generation}

A classical response of a cell to an external stress is the generation of reactive oxygen species. This was indeed the case of bacterial electroeradication. ${ }^{53}$ An oxidative injury was present inducing an alteration in gene expression regulation resulting in a change in the composition of membrane lipids (with a decrease in the percentage of unsaturated fatty acids that are sensitive to oxidation). A decrease in membrane fluidity was induced by the PEF treatment.

\section{Effect of the Buffer pH}

A more complex control by the $\mathrm{pH}$ of the pulsing buffer was present. The nature of membrane damages and their potency to induce cell death depended on the bacterial species and the treatment medium $\mathrm{pH} .{ }^{39,51,54,55}$ The $\mathrm{pH}$ effect was related to the organization of the bacterial envelope. Structural interactions between the wall components were of electrostatic nature and as such, sensitive to the ionization of lateral groups, i.e., to the buffer pH. Electroeradication was not only dependent on the "classical" irreversible membrane electropermeabilization, but the $\mathrm{CW}$ also played a decisive role in the resistance of the bacteria to the stringent electric stress. The wall is an actor in the electrochemical responses of the cell to the electric pulse. ${ }^{56}$

\section{Effect of the Buffer Conductivity}

The ionic strength of the buffer played a critical role in the eradication. Treatment of E. coli suspended in water with a conductivity of $0.2 \mathrm{mS} / \mathrm{cm}$ led to a total bacterial inactivation with twice the number of pulses needed with in phosphate buffer (1 mS/cm) (but at a lower energy cost). The conductivity appeared be one of the most important parameters of the PEF-driven eradication of microbes. ${ }^{57,58}$ Electrostatic interactions present in the wall and in the outer and inner membranes controlled the stability of the cell membrane. Decreasing the medium ionic concentration caused additional pressure on the membrane due to osmotic forces adding more stress to the PEF treatment. 

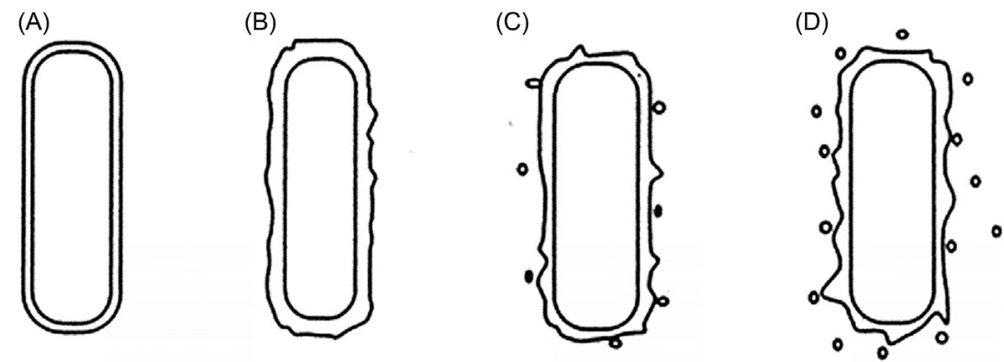

Fig. 3 Effect of an increase in PEF intensity on a L. innocua cell wall; (A) normal cell; (B) cell subjected to $30 \mathrm{kV} / \mathrm{cm}$; (C) cell exposed to $40 \mathrm{kV} / \mathrm{cm}$; and (D) exposure to $50 \mathrm{kV} / \mathrm{cm}$. From Calderón-Miranda, M. L., Barbosa-Cánovas, G. V., Swanson B. G. Transmission electron microscopy of Listeria innocua treated by pulsed electric fields and nisin in skimmed milk. Int. J. Food Microbiol. 1999, 51 (1), 31-38.

\section{Ultrastructural Analysis of PEF Treated Bacteria}

More details on the events affecting the bacterial envelope were obtained by a direct observation of the treated microorganism. Due to the small size of bacteria, optical microscopy is not the best-suited approach. More sensitive methods are offered by electron microscopy studies [scanning electron microscopy (SEM) or transmission electron microscopy (TEM)] on samples that are chemically fixed after the PEF delivery under conditions inducing the bacterial eradication.

L. innocua (rod-shaped, Gram-positive, nonspore-forming bacteria) treated by PEF (from 30 to $50 \mathrm{kV} / \mathrm{cm}$ ) displayed under SEM and TEM observation an increase in the CW roughness, cytoplasmic clumping, leakage of cellular material, and rupture of the CWs and cell membranes. ${ }^{59}$ The level of damages was observed to increase with the intensity of the field treatment. When PEF with electric field intensity of $50 \mathrm{kV} / \mathrm{cm}$ was delivered to L. innocua, damages to the cell membrane were visible without the presence of pores in the wall (Fig. 3). The CW of L. innocua after a PEF treatment with an electric field intensity of $50 \mathrm{kV} / \mathrm{cm}$ appeared blurry. Stronger pulses $(75 \mathrm{kV} / \mathrm{cm}$ ) when delivered to lactobacilli (another gram-positive rod-shaped bacteria) induced a limited number of local ruptures of the wall in parallel to the increase in surface roughness $\left({ }^{60}\right)$.

Ultrastructural changes in Staphylococcus aureus (spherical, Gram-positive) resulted from their PEF treatment. The cell surface was rough after treatment, as observed by scanning electron microscopy (SEM). The CW was broken, and the cytoplasmic contents were leaking out of the cell after exposure to 64 pulses at $60 \mathrm{kV} / \mathrm{cm}$ when observed by TEM. ${ }^{61}$ Another rod-shaped, Gram-positive bacteria (Bacillus pumilus) were treated with a lower field PEF exposure (1000 micropulses at $7.5 \mathrm{kV} / \mathrm{cm})$. Again, SEM observation detected an increase in the surface roughness. Alterations of the cytoplasm, plasma membrane and CW were observed by TEM with the expulsion of cell-debris. ${ }^{62}$ Gram-negative E. coli cells subjected to 60 pulses at $41 \mathrm{kV} / \mathrm{cm}$ were examined by transmission and SEM. Changes in the cytoplasm were present, and the cell surface appeared rough. The cells' OMs were partially destroyed, allowing leaks from the cell cytoplasm. A detachment of the cytoplasm from the cell membrane reflected the severe damages in the wall organization. ${ }^{63}$

Most studies carried out on microorganisms treated by PEF have shown an increase in surface roughness, craters, elongation, disruption of organelles, separation and condensation of cytoplasmic contents, CW breakage, or pore formation. They support a model of pulse-induced eradication where the contribution of the electromechanical stresses on the wall organization should be considered as acting in synergy with the voltage-induced permeabilization of the membrane.

Atomic force microscopy (AFM) is a promising technology to analyze the ultrastructural changes of microoganisms. Information is not limited to the morphological alterations, as with electron microscopy; nanomechanical properties are also recorded. Another advantage is that samples are screened under nondestructive conditions. The effects of PEF on bacteria were probed by AFM on Gram-positive Bacillus pumilus. No chemical fixations of the bacteria were needed for such observations. The change in roughness after the PEF treatment detected by SEM and TEM was confirmed. No mechanical modifications were induced as the stiffness was not affected, but the adhesion properties of the bacteria were dramatically reduced by the eradicating PEF treatment. This reflects a dramatic reorganization of the wall outer layer. ${ }^{64}$

Physico-chemical analyses are indicative of more significant effects as the surface charges and the hydrophobicity appears affected in Gram-positive E. coli $\left[{ }^{65}\right.$ ). In addition, the surface hydrophobicity of the CWs of Gram-negative Bacillus was evaluated by chemical force measurements using a AFM tip functionalized with - $\mathrm{CH} 3$ groups. The adhesion maps revealed that the hydrophobicity present in untreated bacteria disappeared after PEF exposure in a rather homogeneous way on the entire bacterial surface. ${ }^{62}$ In addition, electrophoretic mobility measurements revealed an increase in the surface charge (zeta potential increased from $-34 \mathrm{mV}$ in controls to $-28 \mathrm{mV}$ after PEF.

\section{Conclusions}

Bacterial eradication by PEF appears to be a promising, environment-friendly, cost-effective technology for use in the food and waste water treatment industry. Optimization of the processes has been studied using empirical approaches in different groups 
in the United States and in western Europe. This impacts the availability of industrial devices on the market. But in order for the industry to take full advantage of the methodology, there must be more basic investigation into the biophysical processes supporting the loss of viability in treated microorganisms.

Bacteria are more than a vesicle with a dielectric shell. One should consider the different effects associated with the train of electric pulses and how they may be controlled through manipulation of the electric parameters (field strength, pulse duration, delay between the pulse). Another critical factor is the organization of the cell envelope and its complex response not only to the physical (electromechanical) constraints, but also to metabolic stress associated with high-level membrane electropermeabilization.

\section{Acknowledgements}

This work was supported by the European FP7 (Electroextraction, [FP7-SME-2007-1], Grant agreement no 222220) Projects. Research was conducted in the scope of the EBAM European Associated Laboratory (LEA) and resulted from the networking efforts of the COST Action TD1104 (http://www. electroporation.net).

See also: Eradication of Bacteria Via Electropulsation; Ion Channel Formation in Bilayer Lipid Membranes; Thylakoid Membrane Bioenergetics.

\section{References}

1. Hamilton, W. A.; Sale, A. J. H. Effects of high electric fields on microorganisms. Il. Killing of bacteria and yeasts. Biochim. Biophys. Acta 1967, 148, 789-800. https://doi.org/ 10.1016/0304-4165(67)90053-0.

2. Sale, A. J. H.; Hamilton, W. A. Effects of High Electric Fields on Microorganisms: I Killing of Bacteria and Yeasts. Biochim. Biophys. Acta 1967, 148 (3), 781-878. https:// doi.org/10.1016/0304-4165(67)90052-9.

3. Sale, A. J. H.; Hamilton, W. A. Effects of High Electric Fields on Micro-Organisms: III Lysis of Erythrocytes and Protoplasts. Biochim. Biophys. Acta 1968, 163, 37-43. https:// doi.org/10.1016/0005-2736(68)90030-8.

4. Knorr, D.; Geulen, M.; Grahl, T.; Sitzmann, W. Food Application of High-Electric-Field Pulses. Trends Food Sci. Technol. 1994, 5 (3), 71-75.

5. Barnett, A.; Weaver, J. C. Electroporation: A Unified, Quantitative Theory of Reversible Electrical Breakdown and Mechanical Rupture in Artificial Planar Bilayer Membranes Bioelectrochem. Bioenerg. 1991, 25, 163-182. https://doi.org/10.1016/0302-4598(91)87001-W.

6. Weaver, J. C.; ChizmadzhevYu, A. Theory of Electroporation: A Review. Bioelectrochem. Bioenerget. 1996, 41, $135-216$.

7. Dufresne, K.; Paradis-Bleau, C. Biology and Assembly of the Bacterial Envelope. Adv. Exp. Med. Biol. 2015, 883, 41-76.

8. Silhavy, T. J.; Kahne, D.; Walker, S. The Bacterial Cell Envelope. Cold Spring Harbor Perspect. Biol. 2010, 2 , a000414.

9. Taylor, B. L. Role of Proton Motive Force in Sensory Transduction in Bacteria. Annu. Rev. Microbiol. 1983, 37, 551-573.

10. Jordan, S.; Hutchings, M. I.; Mascher, T. Cell Envelope Stress Response in Gram-Positive Bacteria. FEMS Microbiol. Rev. 2008, 32, 107-146.

11. Holtje, J. V. Growth of the Stress-Bearing and Shape-Maintaining Murein Sacculus of Escherichia Coli. Microbiol. Mol. Biol. Rev. 1998, 62, 181-203.

12. Vollmer, W.; Seligman, S. J. Architecture of Peptidoglycan: More Data and More Models. Trends Microbiol. 2010, $18,59-66$.

13. Lugtenberg, E. J.; Peters, R. Distribution of Lipids in Cytoplasmic and Outer Membranes of Escherichia Coli K12. Biochim. Biophys. Acta 1976, 441, 38-47.

14. Cavalier-Smith, T. Rooting the Tree of Life by Transition Analyses. Biol. Direct 2006, 1, 19

15. Cavalier-Smith, T. Deep Phylogeny, Ancestral Groups and the Four Ages of Life. Philos. Trans. R. Soc. Lond. Ser. B Biol. Sci. 2010, 365, 111-132.

16. Raetz, C. R.; Whitfield, C. Lipopolysaccharide Endotoxins. Annu. Rev. Biochem. 2002, 71, 635-700.

17. Nikaido, H. Molecular Basis of Bacterial Outer Membrane Permeability Revisited. Microbiol. Mol. Biol. Rev. 2003, 67, 593-656.

18. Nakayama, H.; Kurokawa, K.; Lee, B. L. Lipoproteins in Bacteria: Structures and Biosynthetic Pathways. FEBS J. 2012, 279, 4247-4268

19. Klebba, P. E. The Porinologist. J. Bacteriol. 2005, 187, 8232-8236.

20. Weidel, W.; Pelzer, H. Bagshaped Macromolecules-a New Outlook on Bacterial Cell Walls. Adv. Enzymol. Relat. Areas Mol. Biol. 1964, 26, 193-232.

21. Turner, R. D.; Vollmer, W.; Foster, S. J. Different Walls for Rods and Balls: The Diversity of Peptidoglycan. Mol. Microbiol. 2014, 91, 862-874.

22. Pink, D.; Moeller, J.; Quinn, B.; Jericho, M.; Beveridge, T. On the Architecture of the Gram-Negative Bacterial Murein Sacculus. J. Bacteriol. 2000, 182, 5925-5930.

23. Meroueh, S. O.; Bencze, K. Z.; Hesek, D.; Lee, M.; Fisher, J. F.; Stemmler, T. L.; Mobashery, S. Three-Dimensional Structure of the Bacterial Cell Wall Peptidoglycan. Proc. Natl. Acad. Sci. USA 2006, 103, 4404-4409.

24. Mullineaux, C. W.; Nenninger, A.; Ray, N.; Robinson, C. Diffusion of Green Fluorescent Protein in Three Cell Environments in Escherichia Coli. J. Bacteriol. 2006, 188, 3442-3448

25. Swoboda, J. G.; Campbell, J.; Meredith, T. C.; Walker, S. Wall Teichoic Acid Function, Biosynthesis, and Inhibition. Chembiochem 2010, 11, 35-45.

26. Dramsi, S.; Magnet, S.; Davison, S.; Arthur, M. Covalent Attachment of Proteins to Peptidoglycan. FEMS Microbiol. Rev. 2008, 32, 307-320.

27. Vollmer, W. Structural Variation in the Glycan Strands of Bacterial Peptidoglycan. FEMS Microbiol. Rev. 2008, 32, 287-306.

28. Brown, S.; Santa Maria, J. P., Jr.; Walker, S. Wall Teichoic Acids of Gram-Positive Bacteria. Annu. Rev. Microbiol. 2013, 67, 313-336.

29. van der Does, C.; Swaving, J.; van Klompenburg, W.; Driessen, A. J. Non-Bilayer Lipids Stimulate the Activity of the Reconstituted Bacterial Protein Translocase. J. Biol. Chem. 2000, 275, 2472-2478.

30. Pavkov-Keller, T.; Howorka, S.; Keller, W. The Structure of Bacterial S-Layer Proteins. Prog. Mol. Biol. Transl. Sci. 2011, 103, 73-130.

31. Aronsson, K.; Rönner, U.; Borch, E. Inactivation of Escherichia Coli, Listeria Innocua and Saccharomyces Cerevisiae in Relation to Membrane Permeabilization and Subsequent Leakage of Intracellular Compounds due to Pulsed Electric Field Processing. Int. J. Food Microbiol. 2005, 99 (1), 19-32.

32. Bermudez-Aguirre, D.; Fernandez, S.; Esquive, H. I.; Dunne, P. C.; Barbosa-Canovas, G. V. Milk Processed by Pulsed Electric Fields: Evaluation of Microbial Quality, Physicochemical Characteristics, and Selected Nutrients at Different Storage Conditions. J. Food Sci. 2011, 76 (5), S289-S299. https://doi.org/10.1111/j.17503841.2011.02171.x.

33. Bermudez-Aguirre, D.; Dunne, C. P.; Barbosa-Canovas, G. V. Effect of Processing Parameters on Inactivation of Bacillus Cereus Spores in Milk Using Pulsed Electric Fields. Int. Dairy J. 2012, 24 (1), 13-21. https://doi.org/10.1016/j.idairyj.2011.11.003).

34. Fernandez-Molina, J.; Bermudez-Aguirre, D.; Altunakar, B.; Swanson, B. G.; Barbosa-Canovas, G. V. Inactivation of Listeria Innocua and Pseudomonas Fluorescens by Pulsed Electric Fields in Skim Milk: Energy Requirements. J. Food Process Eng. 2006, 29 (6), 561-573. https://doi.org/10.1111/j.1745-4530.2006.00084.x). 
35. Saldana, G.; Puertolas, E.; Condon, S.; Alvarez, I.; Raso, J. Modeling Inactivation Kinetics and Occurrence of Sublethal Injury of a Pulsed Electric Field-Resistant Strain of Escherichia Coli and Salmonella Typhimurium in Media of Different pH. Innov. Food Sci. Emerg. Technol. 2010, 11 (2), 290-298. https://doi.org/10.1016/ j.ifset.2010.01.003

36. Spilimbergo, S.; Dehghani, F.; Bertucco, A.; Foster, N. R. Inactivation of Bacteria and Spores by Pulse Electric Field and High Pressure CO2 at low Temperature. Int. J. Food Microbiol. 2005, 99 (1), 19-32.

37. Sampedro, F.; McAloon, A.; Yee, W.; Fan, X.; Geveke, D. J. Cost Analysis and Environmental Impact of Pulsed Electric Fields and High Pressure Processing in Comparison With Thermal Pasteurization. Food Bioprocess Technol. 2014, 7 (7), 1928-1937. https://doi.org/10.1007/s11947-014-1298-6.

38. Álvarez, I.; Pagán, R.; Condón, S.; Raso, J. The Influence of Process Parameters for the Inactivation of Listeria Monocytogenes by Pulsed Electric Fields. Int. J. Food Microbiol. 2003, 87, 87-95

39. Alvarez, I.; Raso, J.; Palop, A.; Sala, F. J. Influence of Different Factors on the Inactivation of Salmonella Senftenberg by Pulsed Electric Fields. Int. J. Food Microbiol. 2000, $55(1-3), 143-146$

40. Evrendilek, G. A.; Zhang, Q. Effects of Pulse Polarity and Pulse Delaying Time on Pulsed Electric Fields-Induced Pasteurization of E. Coli 0157: H7. J. Food Eng. 2005, 68 (2), 271-276.

41. Guionet, A.; David, F.; Zaepffel, C.; Coustets, M.; Helmi, K.; Cheype, C.; Packan, D.; Garnier, J. P.; Blanckaert, V.; Teissié, J. E. Coli Electroeradication on a Closed Loop Circuit by Using Milli-, Micro- and Nanosecond Pulsed Electric Fields: Comparison Between Energy Costs. Bioelectrochemistry 2015, 103, 65-73. https://doi.org/10.1016/ j.bioelechem.2014.08.021.

42. Cebrián, G.; Mañas, P.; Condón, S. Comparative Resistance of Bacterial Foodborne Pathogens to Non-Thermal Technologies for Food Preservation. Front. Microbiol. 2016, 7, 734. https://doi.org/10.3389/fmicb.2016.00734. eCollection 2016.

43. Golberg, A.; Sack, M.; Teissie, J.; Pataro, G.; Pliquett, U.; Saulis, G.; Töpfl, S.; Miklavcic, D.; Vorobiev, E.; Frey, W. Energy-Efficient Biomass Processing With Pulsed Electric Fields for Bioeconomy and Sustainable Development. Biotechnol. Biofuels 2016, 9, 94. https://doi.org/10.1186/s13068-016-0508-z.

44. Hülsheger, H.; Potel, J.; Niemann, E. G. Electric Field Effects on Bacteria and Yeast Cells. Radiat. Environ. Biophys. 1983, 22 (2), 149-162.

45. Wouters, P. C.; Bos, A. P.; Ueckert, J. Membrane Permeabilization in Relation to Inactivation Kinetics of Lactobacillus Species due to Pulsed Electric Fields. Appl. Environ. Microbiol. 2001, 67 (7), 3092-3101.

46. Khan, S. I.; Blumrosen, G.; Vecchio, D.; Golberg, A.; McCormack, M. C.; Yarmush, M. L.; Hamblin, M. R.; Austen, W. G., Jr. Eradication of Multidrug-Resistant Pseudomonas Biofilm With Pulsed Electric Fields. Biotechnol. Bioeng. 2016, 113 (3), 643-650. https://doi.org/10.1002/bit.25818.

47. Cebrián, G.; Sagarzazu, N.; Pagán, R.; Condón, S.; Mañas, P. Resistance of Escherichia Coli Grown at Different Temperatures to Various Environmental Stresses. J. Appl. Microbiol. 2008, 105 (1), 271-278. https://doi.org/10.1111/j.1365-2672.2008.03745.x.

48. Ohshima, T.; Okuyama, K.; Sato, M. Effect of Culture Temperature on High-Voltage Pulse Sterilization of Escherichia Coli. J. Electrostat. 2002, 55 (3), 227-235.

49. Raso, J.; Condón, S. Environmental Factors Influencing the Inactivation of Listeria Monocytogenes by Pulsed Electric Fields. Lett. Appl. Microbiol. 2002, 35 (6), 489-493.

50. García, D.; Gómez, N.; Condón, S.; Raso, J.; Pagán, R. Pulsed Electric Fields Cause Sublethal Injury in Escherichia Coli. Lett. Appl. Microbiol. 2003, 36 (3), $140-144$.

51. García, D.; Gómez, N.; Mañas, P.; Condón, S.; Raso, J.; Pagán, R. Occurrence of Sublethal Injury After Pulsed Electric Fields Depending on the Micro-Organism, the Treatment Medium ph and the Intensity of the Treatment Investigated. J. Appl. Microbiol. 2005, 99 (1), 94-104.

52. García, D.; Mañas, P.; Gómez, N.; Raso, J.; Pagán, R. Biosynthetic Requirements for the Repair of Sublethal Membrane Damage in Escherichia Coli Cells After Pulsed Electric Fields. J. Appl. Microbiol. 2006, 100 (3), 428-435.

53. Yun, O.; Zeng, X.-A.; Brennan, C. S.; Han, Z. Effect of Pulsed Electric Field on Membrane Lipids and Oxidative Injury of Salmonella typhimurium. Int. J. Mol. Sci. 2016, 17 (8), 1374. https://doi.org/10.3390/ijms17081374.

54. García, D.; Gómez, N.; Mañas, P.; Raso, J.; Pagán, R. Pulsed Electric Fields Cause Bacterial Envelopes Permeabilization Depending on the Treatment Intensity, the Treatment Medium pH and the Microorganism Investigated. Int. J. Food Microbiol. 2007, 113 (2), 219-227.

55. Gómez, N.; García, D.; Alvarez, I.; Condón, S.; Raso, J. Modelling Inactivation of Listeria Monocytogenes by Pulsed Electric Fields in Media of Different pH. Int. J. Food Microbiol. 2005, 103 (2), 199-206.

56. Golberg, A.; Rae, C. S.; Rubinsky, B. Listeria Monocytogenes Cell Wall Constituents Exert a Charge Effect on Electroporation Threshold. Biochim. Biophys. Acta 2012, 1818 (3), 689-694. https://doi.org/10.1016/j.bbamem.2011.11.003.

57. Jarayam, S.; Castle, G. S. P.; Margaritis, A. The Effects of High Fields DC Pulse and Liquid Medium Conductivity on Survivability of Lactobacillus Brevis. Appl. Microbiol. Biotechnol. 1993, 40, 117-122.

58. Vega-Mercado, H.; Pothakamury, U. R.; Chang, F. J.; Barbosa-Cánovas, G. V. Inactivation of Escherichia Coli by Combining pH, Ionic Strength and Pulsed Electric Fields Hurdles. Food Res. Int. 1996, 29, 117-121.

59. Calderón-Miranda, M. L.; Barbosa-Cánovas, G. V.; Swanson, B. G. Transmission Electron Microscopy of Listeria Innocua Treated by Pulsed Electric Fields and Nisin in Skimmed Milk. Int. J. Food Microbiol. 1999, 51 (1), 31-38.

60. Yeo, S. K.; Liong, M.-T. Effects and Applications of sub-Lethal Ultrasound, Electroporation and UV Radiations in Bioprocessing. Ann. Microbiol. 2012, 63 (3). https://doi.org/ 10.1007/s13213-012-0559-8

61. Pothakamury, U. R.; Barbosa-Cánovas, G. V.; Swanson, B. G.; Spence, K. D. Ultrastructural Changes in Staphylococcus Aureus Treated With Pulsed Electric Fields. Food Sci. Technol. Int. 1997, 3, 113-121.

62. Pillet, F.; Formosa-Dague, C.; Baaziz, H.; Dague, E.; Rols, M. P. Cell Wall as a Target for Bacteria Inactivation by Pulsed Electric Fields. Sci. Rep. 2016, 6, 19778. https:// doi.org/10.1038/srep19778.

63. Dutreux, N.; Notermans, S.; Wijtzes, T.; Góngora-Nieto, M. M.; Barbosa-Cánovas, G. V.; Swanson, B. G. Pulsed Electric Fields Inactivation of Attached and Free-Living Escherichia Coli and Listeria Innocua Under Several Conditions. Int. J. Food Microbiol. 2000, 54 (1-2), 91-98.

64. Dague, E. Atomic Force Microscopy to Explore Electroporation Effects on Cells. In Handbook of Electroporation, Springer: New York, 2016 ; pp 1-13.

65. Ukuku, D. 0.; Yuk, H. G.; Zhang, H. Hydrophobic and Electrostatic Interaction Chromatography for Estimating Changes in Cell Surface Charge of Escherichia Coli Cells Treated With Pulsed Electric Fields. Foodborne Pathog. Dis. 2011, 8 (10), 1103-1109.

\section{Further Reading}

Raso, J., Heinz, V., Eds. Food Engineering Series; Pulsed Electric Fields Technology for the Food Industry: Fundamentals and Applications, Springer: Berlin, 2006. ISBN 978-0387-31053-4.

Ahmed, J., Shafi ur Rahman, M., Eds. Handbook of Food Process Design, 1st ed.; Blackwell: Hoboken, NJ, 2012; pp 1078-1106.

Miklavcic, D., Ed. Handbook of Electroporation, Springer: Berlin, 2017. ISBN 978-3-319-26779-1.

Nickoloff, J. A., Ed. Electroporation Protocols for Microorganisms: Methods in Molecular Biology 47, Springer: Berlin, 1995.

Eynard, N., Teissie, J., Eds. Electrotransformation of Bacteria, Springer: Berlin, 2000. ISBN: 978-3-662-04305-9, 978-3-642-08593-2. https://doi.org/10.1007/978-3-66204305-9. 


\section{Relevant Websites}

www. bioelectrochemical-soc.org/.

www. odu. edu/bioelectrics/ibc.

www.pulsedpower.eu/bioelectrics/bio_index.html. 